SHORT REPORT

\title{
Clinically evidenced unilateral dissociation of saccades and pursuit eye movements
}

\author{
M Onofri, D lacono, A L Luciano, K Armellino, A Thomas
}

J Neurol Neurosurg Psychiatry 2004;75:1048-1050. doi: 10.1136/jnnp.2003.025163

A patient affected by an ischaemic lesion of the right medial thalamic nucleus presented with a uniocular dissociation of upward vertical saccades and pursuit movement, with absent upward vertical saccades in the left eye. Clinical observations were confirmed by magnetic field scleral search coils analysis. During the vertical eye movement the patient denied any diplopia, thus suggesting a transient visual suppression in the left eye.

S everal ocular movement disorders secondary to vascular thalamic lesions have been described in previous studies, including blepharospasm, pseudo-sixth nerve palsy, bilateral internuclear ophthalmoplegia with ptosis, vertical gaze dysfunction with the "vertical one-and-a-half syndrome", and isolated eyelid tremor..$^{1-5}$ These disturbances result from involvement of the intralaminar and dorsomedial nuclei, often with coexisting lesions of the upper midbrain, or of unilateral paramedian thalamic nuclei. ${ }^{12}$ We describe a case of a unilateral dissociation between saccade and pursuit eye movements without diplopia in a patient with circumscribed infarction of the medial thalamic nucleus.

\section{CASE REPORT}

The patient was a 56 year old housewife who, two months previously, had an episode consisting of loss of consciousness and confusion followed by diplopia for two days. Laboratory examinations were normal and magnetic resonance imaging (MRI) showed a thalamic lesion. The patient complained of an eye movement disturbance that caused only an "aesthetic" discomfort: when she looked upwards-that is, when she was sitting in an armchair, for example, and had to look up at a standing interlocutor-a squint appeared, lasting for a few seconds, which was not accompanied by diplopia. The eye movement disorder persisted unmodified in the ensuing three years, and only two years after the episode was an increase in antiphospholipid antibodies detected (80 GPL-G class phospholipid units with immunoassay test).

MRI repeated two years after the episode, using a Siemens Magneton Vision Scan operating at $1.5 \mathrm{~T}$, with high resolution $(1 \mathrm{~mm}) \mathrm{TS}$-echo T2 and T1 weighted sequences, showed an isolated $\mathrm{T} 2$ hyperintense and T1 hypointense lesion of the right medial thalamus (fig 1), overlapping in size with the lesion shown on the first MRI. There was no evidence of extension to the upper midbrain. Co-registration of TIRMMRI to a digitalised three dimensional stereotactic atlas ${ }^{6}$ showed that the patient's thalamic lesion affected the right medial nucleus exclusively.

\section{CLINICAL FINDINGS}

In primary position, the patient had modest esotropia without diplopia (fig l; and see the website video available at http://www.jnnp.com/supplemental). The pupils were isochoric, the photomotor reflex was normal, and diplopia was absent in any spatial direction of gaze. Eye fields (tested with Goldman perimetry), colour perception, and visual acuity were normal in both eyes. The oculocephalic reflex elicited full upward eye movements, Bell's phenomenon was normally present, and convergence was present accompanied by miosis. Vertical optokinetic nystagmus (OKN, tested with a tape) was absent, but stimuli did not elicit convergence nystagmus. Horizontal OKN was normal. Spontaneous or gaze evoked nystagmus was absent, and horizontal eye movements and downward gaze were normal, but in upward gaze the left eye was locked in the primary position if the target moved vertically faster than $30 \%$ (fig 1 ).

After one to two seconds a vertical slow movement realigned the eyes. The patient specifically denied any diplopia during the upward fast movement of the right eye.

The website material shows videotaped eye movements obtained with stimuli moving at $20 \%$ and $62 \%$ s. During the videotape the examiner moves the target placed at $57 \mathrm{~cm}$ from the patient's eyes on a range subtending $50 \mathrm{~cm}$ (corresponding to a $50^{\circ}$ visual angle). The slow movement is carried out in $2.4 \mathrm{~s}$, corresponding to a target speed of $20 \%$; the fast movement is carried out in $0.8 \mathrm{~s}$, corresponding to $62 \%$ speed.

\section{LABORATORY EXAMINATION}

To understand why the patient denied diplopia, we tested the perception of visual targets presented on a computer screen subtending a $31^{\circ}$ visual angle (STIM System, Neuroscan Inc, $2001)^{7}$ during vertical eye movements. Targets consisted of different numbers or animal figures presented simultaneously on the left and right upper screen quadrants. A piece of cardboard placed between the nasion and the screen separated the left and right eye fields. The patient was instructed to fixate on a dot on the lower border of the screen and then to fixate on the targets, announced by a loud tone, appearing on the upper part of the screen $\left(25^{\circ}\right.$ visual angle above the fixation spot). Ten targets were presented for 0.3 , 0.9 , and $1.5 \mathrm{~s}$; the eyes were tested simultaneously (30 targets) and separately (with a patch covering the contralateral eye, 30 targets per eye). With the right eye the patient recognised $100 \%$ of the targets in the right upper quadrant during monocular and binocular presentations. With the left eye, she missed $100 \%$ of targets in the left upper quadrant when the presentation lasted for 0.3 and $0.9 \mathrm{~s}$ (monocular and binocular). When the presentation lasted for $1.5 \mathrm{~s}$ she missed $80-90 \%$ of targets.

Eye movements were tested using the magnetic field scleral search coil (MFSSC) method. ${ }^{8} 9$ Visual stimuli were red spots projected onto a tangent screen at a distance of 95 $\mathrm{cm}$. A central fixation point was switched off $200 \mathrm{~ms}$ before the onset of targets located $25^{\circ}$ to the right, left, up, and down central fixation. For pursuit movements the fixation point moved with a speed of 5, 10, 15, and $25 \%$ s. Resolution was 

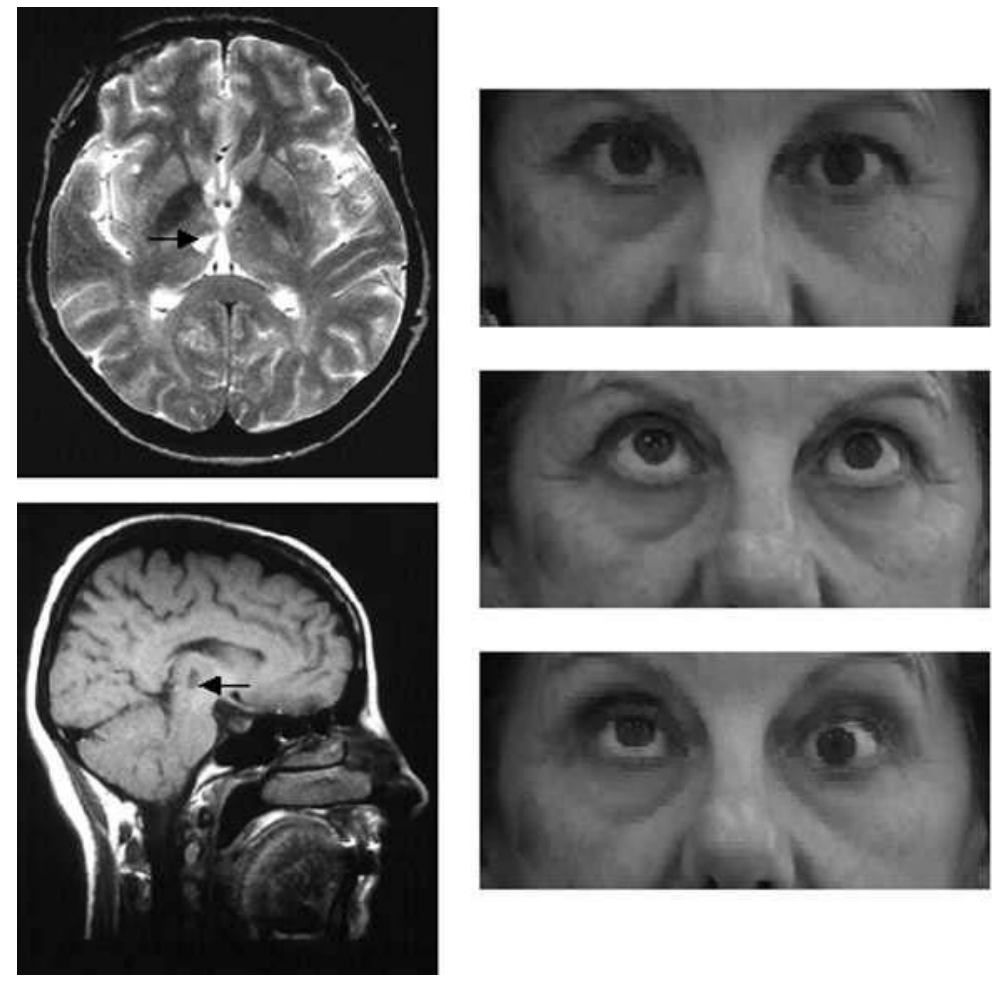

Primary position
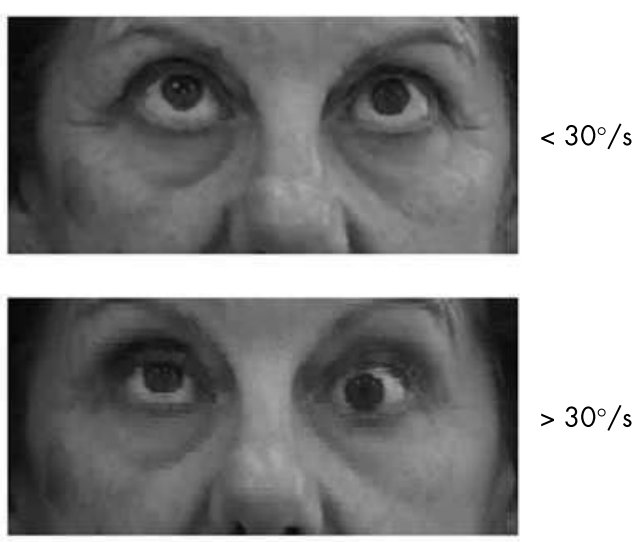

Figure 1 Axial (T2) and (T1) sagittal T1 weighted magnetic resonance images of the left thalamic lesion (arrows). Notice that only the medial thalamic area is involved. Right: photographs (from the video) in primary position, top; during upward gaze to a stimulus moving at $10 \% \mathrm{~s}$, middle; and in response to a stimulus moving faster than $30 \% \mathrm{~s}$, bottom.

$\mathrm{l}^{\prime}$ arc. Signals were filtered at 0.5 to $250 \mathrm{~Hz}$ and digitised at $1024 \mathrm{~Hz}$ (Neuroscan Synamps system).

The onset latency (mean (SD)) of lateral saccades was 219 (28) and 221 (33) ms; downward saccade latency was 231 (38) $\mathrm{ms}$ in the right eye (RE) and 229 (28) ms in the left eye (LE). RE upward saccades had a latency of 250 (38) ms; in LE the eye movement onset latency was 1027 (189) ms (20 trials).

$\mathrm{V}_{\max }{ }^{89}$ was $406(39) \% \mathrm{~s}$ RE, $400(42) \%$ LE for lateral saccades, and $388(38) \%$ RE, 391 (29)\% LE for downward saccades. The RE upward saccade $V_{\max }$ was $388(29) \%$, while the upward delayed LE $\mathrm{V}_{\max }$ was $53 \%$. Slow pursuit test elicited normal full range movements in both eyes.

All measurements but left eye upward saccades were within the normal ranges of our laboratory $( \pm 1$ SD), corresponding to values commonly described in published reports. ${ }^{10} 11$

\section{DISCUSSION}

The patient described here is an unprecedented case of monocular elevation palsy with dissociated saccades and slow movements, evidenced by simple clinical tests.

The dissociation between saccades and slow movements and the preservation of oculocephalic reflexes suggests that the monocular elevation palsy is of supranuclear origin. The dissociation between saccades and pursuit argues against vertical eye movement resulting from inferior orbital restriction $^{12}$ or from constriction of the superior oblique pulley system-that is, Brown's syndrome. ${ }^{13}$

Previous clinical case reports have not provided evidence of this disturbance in thalamo-mesencephalic lesions. Bilateral vertical gaze palsy, or the vertical one-and-a-half syndrome, was previously described in thalamic lesions. ${ }^{1}{ }^{114}$ Monocular elevation palsy with internuclear ophthalmoplegia and ptosis have been described in one case,,$^{15}$ and monocular elevation paresis for both saccade and pursuit movements in another, ${ }^{16}$ dependent on paramedian or lower midbrain lesions.

The monocular elevation palsy syndrome has been called the prenuclear syndrome of the oculomotor nucleus, or the supranuclear "double elevator palsy", ${ }^{16}{ }^{17}$ and attributed to lesions of the upward gaze efferent fibres of the rostral interstitial nucleus of the medial longitudinal fasciculus (riMLF).

Only one report has described dissociation of upward saccades and pursuit in the relatively "spared" eye of a patient with the vertical one-and-a-half syndrome. ${ }^{18}$ In that patient the spared eye, corresponding to the half of the syndrome, could not effect vertical saccades, and the other eye could not move vertically at all. Lesions in that case included the thalamus and the midbrain.

The localising property of vertical gaze palsies has led some investigators to claim that patients with vertical gaze disturbances from thalamic lesions always have lesions extending to the upper midbrain as well. ${ }^{19}$

The absence of saccades and preservation of pursuit in our patient, with absence of other oculomotor disturbances, provides a natural experiment that is undoubtedly difficult to explain. As the riMLF is considered to be the supranuclear relay for both saccade and pursuit, ${ }^{16}{ }^{17}$ we must hypothesise that a microscopic lesion, smaller than the $1 \mathrm{~mm}$ resolution limit of our MRI, might have affected only the supranuclear fibres for vertical saccades, sparing the other fibres in the crowded rostral mesencephalic area. However, previous case reports have shown that lesions are always detectable when there are eye movement disturbances.

Alternatively, as careful observation of MRI in our patient showed only a lesion localised in the contralateral medial thalamic nucleus-in the territory of the posterior choroidal artery, ${ }^{1}$ above intralaminar nucleus, and apparently not extending into the midbrain-it could be hypothesised that the medial thalamic areas are involved in the generation of 
upward saccades. A clinical report showed undissociated vertical gaze disturbance in 12 patients affected by ischaemic infarction in the territory of the posterior thalamo-subthalamic paramedian artery, and absence of optokinetic nystagmus in three patients with infarcts of the posterior choroidal artery. ${ }^{1}$ Experimental studies in monkeys ${ }^{20}{ }^{21}$ suggest that thalamic nuclei take part in the genesis of saccades.

The other relevant finding in this case study is that the patient denied any diplopia during vertical eye movements, despite the evident saccadic dissociation and squint appearance. Diplopia was instead described in prenuclear syndromes caused by midbrain lesions. ${ }^{15}{ }^{16}$ By presenting targets during vertical eye movements we could show that target perception was absent or abnormal only in the left eye. I suggest that transient visual suppression might explain the absence of diplopia.

Saccades are known to suppress vision transiently. ${ }^{22}$ The perception abnormality observed in this patient only in the left eye concomitantly with right eye saccades suggests a clinical condition in which visual suppression may be dissociated from the actual presence of saccades.

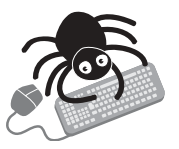

The video shows clinical tests of eye movements. In the first part, the stimulus is slowly moved upwards (range of movement $50 \mathrm{~cm}$, distance from the eye $57 \mathrm{~cm}$; $1 \mathrm{~cm}$ at this distance is $1^{\circ}$ of visual angle; duration of motion $2.4 \mathrm{~s}$, speed $<25^{\circ} / \mathrm{s}$ ). In the second, part the speed of motion is above $50 \%$ s (duration of motion $0.85 \mathrm{~s})$.

\section{Authors' affiliations \\ M Onofri, D lacono, A L Luciano, K Armellino, A Thomas, \\ Neurophysiopathology, University Chieti-Pescara, Pescara, Italy \\ Competing interests: none declared}

Correspondence to: Professor Marco Onofrj, Neurophysiopathology, Department of Oncology and Neuroscience, University "G D'Annunzio" Chieti-Pescara, Via Fonte Romana, 65124 Pescara, Italy; onofrj@unich.it

Received 1 August 2003

In revised form 22 September 2003

Accepted 12 October 2003

\section{REFERENCES}

1 Bogousslavsky J, Regli F, Uske A. Thalamic infarcts: clinical syndrome, etiology, and prognosis. Neurology 1988;38:837-48.

2 Jungehulsing GJ, Ploner CJ. Eyelid tremor in a patient with unilateral paramedian thalamic lesion. J Neurol Neurosurg Psychiatry 2003;74:356-8.

3 Bogousslavsky J, Regli F. Upgaze palsy and monocular paresis of downward gaze from ipsilateral thalamo-mesencephalic infarction: a vertical "one-anda-half" syndrome. J Neurol 1984;231:43-5.

4 Lee MS, Marsden CD. Movement disorders following lesions of the thalamus or subthalamic region. Mov Disord 1994;9:493-507.

5 Powers JM. Blepharospasm due to unilateral diencephalon infarction. Neurology 1985; 35:283-4.

6 Niemann K, Mennicken VR, Jeanmonod D, et al. The Morel stereotactic atlas of the human thalamus: atlas-to-MR registration of internally consistent canonical model. Neuroimage 2000;12:601-16.

7 STIM System. User's guide. Scan 4.2 Version. Synamps System. EEG and evoked potential workstation manual. Sterling, VA: Neuroscan Inc, 2001.

8 Robinson DA. A method of measuring eye movements using a scleral search coil in a magnetic field. IEEE Trans Biomed Electronics 1963;10:137-45.

9 Flipse JP, Straathof CSM, Van der Steen J, et al. Binocular saccadic eye movements in multiple sclerosis. J Neurol Sci 1997; 148:53-65.

10 Leigh RJ, Zee DS. The saccadic system. In: The neurology of eye movements, 3rd ed. New York: Oxford University Press, 1999:90-134.

11 Walker MF, Zee DS. Eye-movement recordings in the evaluation of ophthalmologic and neurologic disorders. Curr Opin Ophthalmol 1999;10:401-4.

12 Metz HS. Double elevator palsy. J Pediatr Ophthalmol Strabismus 1981;18:31-5.

13 Wright KW. Brown's syndrome: diagnosis and management. Trans Am Ophthalmol Soc 1999;97:1023-109.

14 Bogousslavsky J, Misklossy J, Deruaz JP, et al. Unilateral left paramedian infarction of thalamus and midbrain: a clinico-pathological study. J Neurol Neurosurg Psychiatry 1986;49:686-94.

15 Bogousslavsky J, Regli F, Ghika J, et al. Internuclear ophthalmoplegia, prenuclear paresis of contralateral superior rectus, and bilateral ptosis. J Neurol 1983;230:197-203.

16 Hommel M, Bogousslavsky J. The spectrum of vertical gaze palsy following unilateral brainstem stroke. Neurology 1991;41:1229-34.

17 Buttener-Ennever JA, Buttner U, Cohen B, et al. Vertical gaze paralysis and the rostral interstitial nucleus of the medial longitudinal fasciculus. Brain 1982; 105:125-49.

18 Deleu D, Buissert T, Ebinger G. Vertical one-and-a-half syndrome. Supranuclear downgaze paralysis with monocular elevation palsy. Arch Neurol 1989:46:1361-63.

19 Siatkowski RM, Schatz NJ, Sellitti TP, et al. Do thalamic lesions really cause vertical gaze palsies? J Clin Neurophysiol 1993;13:90-3.

20 Robinson DL, McClurkin JW. The visual superior colliculus and pulvinar. In: Wurtz RH, Goldberg ME, eds. The neurobiology of saccadic eye movements. Amsterdam: Elsevier, 1989:337-60

21 Bschlag J, Schlag-Rey M. The central thalamus. In: Wurtz RH, Goldberg ME, eds. The neurobiology of saccadic eye movements, chapter 10. Amsterdam: Elsevier, 1989:361-90.

22 Campbell FW, Wurtz RH. Saccadic omission: why we do not see a grey out during a saccadic eye movement. Vision Res 1978;18:1297-303. 